\title{
The Mediating Effect of Adult Attachment on the Relation between Childhood Experiences and Intimate Partner Perpetration and Victimization in Thailand
}

\author{
Saranya Sriyothin ${ }^{1} \&$ Kakanang Maneesri ${ }^{1}$ \\ ${ }^{1}$ Faculty of Psychology, Chulalongkorn University, Bangkok, Thailand \\ Correspondence: Saranya Sriyothin and Kakanang Maneesri, Faculty of Psychology, Chulalongkorn University, \\ 7th Fl. Borommaratchachonnanisrisattapat Bldg., Rama 1 Rd. Pathumwan, Bangkok, 10330 Thailand. Tel: \\ 666-2218-1191. E-mail: nenechan54@hotmail.com; kakanang.M@chula.ac.th
}

Received: November 10, 2016

doi:10.5539/ass.v13n2p75
Accepted: December 4, 2016 Online Published: January 19, 2017

URL: http://dx.doi.org/10.5539/ass.v13n2p75

\begin{abstract}
The current study investigated the effects of exposure to abusive and supportive childhood experiences on intimate partner perpetration and victimization using adult attachment as a mediator. A sample of 1010 heterosexual adults completed measures of the Exposure to Abusive and Supportive Environments Parenting Inventory (EASE-PI), Experiences in Close Relationships-Revised (ECR-R), Adult Attachment Questionnaire, and the Revised Conflict Tactics Scales (CTS2). Structural equation modeling revealed that abusive childhood experiences affected perpetration and victimization directly and indirectly through anxiety over abandonment and avoidance of intimacy, supportive childhood experiences affected perpetration through anxiety over abandonment, and affected victimization through both anxiety over abandonment and avoidance of intimacy. The implications suggested a decrease in abusive childhood experiences and an increase in supportive childhood experiences are necessary to reduce IPV perpetration and victimization.
\end{abstract}

Keywords: adult attachment, childhood experiences, intimate partner violence, perpetration, victimization

\section{Introduction}

Intimate partner violence (IPV) is a serious and prevalent problem in Thailand and the rest of the world both in terms of the perpetration and victimization. Thailand passed its first-ever domestic violence law in 2007 to punish perpetrators and protect victims who have been abused by their partners. However, legislation has not stopped the increase in domestic violence which has been on the rise for the past ten years.

According to UN Women (2011) out of 41 countries surveyed, Thailand was ranked second for countries that view physical violence by men against women justifiable. Moreover, of 75 countries surveyed between 2000-2010, Thailand ranked 36th for physical violence and 7th for sexual violence.

There are similarities and differences in the IPV research done in Thailand compared to those conducted in research-leading countries of the West. Most research has focused on male-to-female violence in which prevalence and forms of IPV have often been explored. However, Thai researchers have rarely studied perpetration and victimization in the same samples or examined IPV using longitudinal studies as opposed to cross-sectional methods and none have investigated the possible contribution to IPV by abusive and supportive childhood experiences with structural equation model analysis.

This study aimed to test antecedents of IPV including abusive childhood experiences from caretakers and insecure adult attachment styles. Furthermore, we examined whether supportive childhood experiences was a protective factor against IPV.

\subsection{Antecedents of IPV}

Social psychologists often explain IPV in terms of social learning theory. Bandura and Walters (1963) stated that children can imitate the models they observe, and that modeling reinforces behavior this way. When children observed aggressive models who seemly received rewards for their aggression, children's aggressive behaviors were significantly higher than those who observed models receiving punishment for their aggression. Generally, people seek to gain rewards and avoid punishment by observing what happens to others; they can learn about 
behavioral outcomes by observing. Later, Bandura (1973) suggested that parents are the most important models for their children in parent-child relationships. If family members deal with their tension, frustration, and anger in violent ways, their children may learn to respond to these situations in the same manner. Some boys from violent families learn that men are perpetrators and there is no need to respect women because they observed violent relationships and maternal abuse (Garvey, McDowell, \& Streit, 1999). Likewise, children who had abusive childhood experiences were more prone to become perpetrators and victims because they believed that violence was an acceptable conflict management method and model in adults (Feldman, 1997).

Family-of-origin aggression of witnessing interparental violence and child physical maltreatment are risk factors of IPV. It was found that males who experienced child abuse or physical assault were at high risk of perpetration, but those with a history of severe childhood physical assault or having witnessed interparental violence stood an increased risk of perpetration and victimization. Meanwhile, females who witnessed interparental violence, especially physical assault were at high risk of perpetration, but those who experienced child abuse were one and a half times more prone to perpetration and victimization (McKinney, Caetano, Ramisetty-Mikler, \& Nelson, 2009; O'Leary \& Curley, 1986).

Ministry of Social Development and Human Security and Thailand UNICEF (2015) revealed how child maltreatment consequently affected IPV. Short-term consequences of child maltreatment were physical problems (e.g., injury, and delayed development) and psychological problems (e.g., depression, low self-esteem, hopelessness, anxiety, low social skills, aggressive behavior, and disobedience because of accumulated anger and stress). On the other hand, the long-term consequences were that they were more likely to perpetrate their partners as adults because they thought violence was common, and displayed aggressive behavior such as bullying, sexual abuse, and partner violence; even punishing their own children in a manner they had experienced themselves. Moreover, public policy has often focused on the protection of Thai families by law enforcement but authorities have had insufficient expertise with domestic violence which means it is often difficult to prosecute perpetrators. Thailand also lacks research in domestic violence, and instead studies focus on preventive programs and the promotion of love and warmth in the family institution, including knowledge of conflict management without violence. Thus, childhood experience is a very important antecedent of IPV. While there is strong evidence of the negative effects of abusive childhood experiences, there is very little evidence on whether supportive parenting can reduce the occurrence of violence in adulthood. The current research aims to address this question.

Researchers are also interested in some personality traits that affect IPV. Bowlby (1984) viewed the attachment patterns between children and caregivers as similar to adult attachments in that adults also need support and feelings of security from committed persons when they are faced with troubling situations. They are anxious while their commitments are threatened, and may emotionally respond with behaviors of anger and protest. Threats to their commitment can be caused by many factors such as anxiety over fear that their partner will leave them or be unfaithful. Bowlby mentioned that if people respond to commitment threats in appropriate ways and level, expressions of anger could be advantageous and adaptive because these expressions could protect themselves from danger, discourage enemies, and threaten their partner to protect the value of their relationship. However, when not managed well, expressions of anger or protest could become IPV. In addition, Lawson (2008) stated that people who had insecure attachments found it difficult to cope with interpersonal problems and were more likely to be perpetrators, including those who have witnessed interparental violence or experienced childhood physical abuse. Moreover, Marcus and Swett (2003) found that abusive husbands with anxious attachments and fears of neglect had insecure romantic relationships, needed high levels of trust, but felt low levels of intimacy towards their wives.

Ainsworth, Blehar, Waters, and Wall (1978) categorized attachment styles into three patterns, a secure attachment style is demonstrated in a child being satisfied when caregivers respond appropriately. An avoidant attachment pattern is shown by cold, uncaring, and inappropriate interactions with primary caregivers. If caregivers respond to children inconsistently or unpredictably, children may develop an anxious-ambivalent attachment pattern. Later, Ainsworth et al. found that those with secure attachment patterns trusted in their partners, those with avoidant patterns accepted their partner's affectionate responses the least, and those with anxious-ambivalent patterns were the most concerned with their partner's commitment to the relationship. Attachment style is often categorized in anxiety and avoidance dimensions. A low sum score from both dimensions would be classified as a secure style. The anxiety dimension corresponds to emotional processing, monitoring, and evaluating of threat signals, whereas the avoidance dimension corresponds to strategies that a person uses to control his or her attachment needs. Many researchers have tried to understand IPV by studying adult attachment styles. Orcutt, Garcia, and Pickett (2005) found that female perpetrators and victims are highly 
anxious. Women high in anxiety but low in avoidance are perpetrators more often than those who are high in both anxiety and avoidance. Godbout, Dutton, Lussier, and Sabourin (2009) found from their study of 644 Canadian adults that abusive childhood experiences affected IPV directly and indirectly through anxiety over abandonment and avoidance of closeness.

Based on the findings cited above, we assumed that an insecure attachment style affects perpetration and victimization. Additionally, we expected that abusive childhood experiences mediated by adult attachment styles, contributes to IPV, whereas supportive childhood experiences contribute in the opposite direction. Nevertheless, this research separately analyzed IPV perpetration and victimization models because it aimed to study and compare the effects of antecedent variables to perpetration and victimization, so as to suggest proper implications to prevent IPV perpetration and victimization.

\section{Method}

\subsection{Participants}

The participants were 1010 adults (454 male and 556 female) recruited by cluster random sampling from northern, northeastern, southern, and central regions of Thailand. Two provinces from each region were recruited by simple random sampling. Thus, the samples were selected by stratified random sampling. The researchers contacted managers or supervisors from both government and private organizations to allow for data collection of adults that met the following criteria; adults were over 18 years old and had been in, or were currently in a relationship with a heterosexual partner for at least 6 months. Control variables of this study consisted of the adult's age, their relationship period, the presence of a heterosexual relationship, and a voluntary admission of experiencing adult IPV behavior. Those who met the criteria participated voluntarily and had to be willing to complete questionnaires, read an invitation to participate and a research information sheet, and then finally sign an informed consent form. The Institutional Review Boards (IRB) at Chulalongkorn University reviewed and approved the study. Participants could refuse or withdraw from this study at any time and did not receive any negative ramifications from their supervisors. The completed questionnaires were collected confidentially and anonymously. All participants were offered a list of phone numbers of social and counseling services for IPV.

The numbers of male and female participants were approximately equal; 55.05\% were female. Participants' ages ranged from 18 to over 50 years. There were $58.22 \%$ in registered marriages, $16.93 \%$ in unregistered marriage, $16.63 \%$ in non-cohabitating, unmarried relationships, and $8.22 \%$ in cohabitating, unmarried relationships. Regarding education levels, most participants $(45.74 \%)$ had the same education (undergraduate degree) level as their partners, followed by $18.51 \%$ who had a degree higher than their partners, and $15.74 \%$ who had a degree lower than their partners. Regarding income, half of them made the same amount as their partners which was between 10 000-20 000 baht per month (about \$333-666 US), followed by those with lower incomes than their partners (21.58\%), and those with higher incomes than their partners $(20.69 \%)$.

A cross-sectional survey research design was implemented in the study. These questionnaires explored demographic data, prevalence and forms of IPV perpetration and victimization, inquired into childhood experiences, and examined their adult attachment styles. They responded on paper and returned their responses.

\subsection{Measures}

Three variables were of primary interest in this study: childhood experiences, adult attachment styles, and IPV perpetration and victimization. These variables were measured using the scales explained below.

\subsubsection{Supportive and Abusive Childhood Experiences}

Participants were assessed with the Exposure to Abusive and Supportive Environments Parenting Inventory (EASE-PI), composing of three constructs measuring a supportive factor (18 items: love/support, promotion of independence, role-modeling and fairness), and three constructs measuring an abusive factor (18 items: psychological aggression, physical assault, and sexual coercion) (Nicholas \& Bieber, 1997). They were also assessed with the Parent-Child Conflict Tactics Scales (CTSPC) as a measure of abusive factors (12 items). The CTSPC consists of two constructs measuring nonviolent discipline and neglect (Straus, Hamby, Finkelhor, Moore, \& Runyan, 1998). Participants rated how often they experienced the described behaviors of their caretakers before they were 18 years old on a 7 -point scale ranging from $0=$ never, $1=$ once, $2=$ twice, $3=3-5$ times, $4=6-10$ times, $5=11-20$ times, or $6=$ more than 20 times. Sample items include "Did things that let you know she (he) loved you" for supportive experiences and "Insulted or swore at you" for abusive experiences. Scale scores were computed by totaling the frequency scores for supportive and abusive childhood experiences separately. We investigated the discriminant validity between the high and low groups of these scales with an independent $t$-test. Later, we investigated the items with corrected item-total correlation (CITC), and the 
construct validity of these scales with confirmatory factor analysis (CFA) and tested scale reliability with Cronbach's alpha. The 18-item scale from EASE-PI and CTSPC consists of three constructs measuring a supportive factor ( 9 items-love/supporting, independency promotion, and modeling/fairness), and three constructs measuring an abusive factor (9 items-psychological aggression, physical assault, and neglect), validating the factor structure of these instruments. This measurement model was fitted to the data, $\chi^{2}(8)=14.19$, $p=.077$, CFI $=.98$, RMSEA $=.063$. Reliabilities of subscales on supportive and abusive factors were $.88, .91, .92, .70, .60$, and .66 , respectively. The total scale reliability was .81 .

\subsubsection{Adult Attachment Style}

The scale was translated and adapted from the Experiences in Close Relationships-Revised (ECR-R) Adult Attachment Questionnaire (Fraley, Waller, \& Brennan, 2000) by Imthanavanich (2002). The 36-item measure composed of two dimensions, attachment anxiety and avoidance. Later, Imthanavanich added more items which increased the scale's length of each dimension to 18 items and administered item analysis with an independent $t$-test and CITC, producing a 48-item measure. Participants indicated the extent to which each statement is true of their own behavior in intimate relationship on a 5 -point scale ranging from $1=$ not true at all to $5=$ very true. Anxious attachment reflects the respondent's feelings of closeness with their partners, such as "In relationships, I often worry that my partner does not really love me". An example of an avoidant attachment statement is "I find it relatively easy to get close to my partner" (negative loading). Reliabilities of the 2 dimensions are .90 and .90 . Finally, Tantong (2005) took it to investigate concurrent validity by correlating testing to a scale, which Parapop (2003) developed from the Relationship Scales Questionnaire (RSQ) (Griffin \& Bartholomew, 1994) and both correlated highly. The present study's internal consistency reliability as measured by Cronbach's alpha for anxiety and avoidance scale scores was .92 and .86 , respectively.

\subsubsection{IPV Perpetration and Victimization}

Straus, Hamby, Boney-Mccoy, and Sugarman's (1996) revised Conflict Tactics Scales (CTS2) was used to assess IPV perpetration and victimization, which consisted of 60 items. We investigated item analysis with an independent t-test and CITC, with a total of 52 items. Later, we tested the construct validity with CFA and selected 32-items with high factor loading. It consisted of 16 items measuring self-to-partner behavior, and 16 items measuring partner-to-self behavior. Participants rated how often they or their partners behaved in the manner described in each statement within the past 12 months on a scale ranging from $0=$ never, $1=$ once, $2=$ twice, $3=3-5$ times, $4=6-10$ times, $5=11-20$ times, or $6=$ more than 20 times. Participants' mean self-to-other and mean other-to-self behavior scores formed our IPV perpetration and victimization measures, respectively. We found four constructs including psychological aggression, physical assault, sexual coercion, and injury, consistent with the original version. The perpetration measurement model was fitted to the data: $\chi^{2}(1)=2.42, p$ $=.120, \mathrm{CFI}=0.99, \mathrm{RMSEA}=.085$. Reliabilities for the four subscales were $.86, .77, .52$, and .67 , respectively. The total scale reliability was .82 . Similarly, the victimization measurement model was perfectly fitted to the data: $\chi^{2}(1)=0.04, p=.844$, CFI $=1.00$, RMSEA $=.000$. Reliabilities of four subscales were $.86, .77, .52$, and .67 , respectively. The total scale reliability was .82 .

\section{Results}

\subsection{IPV Perpetration and Victimization}

For the prevalence of IPV perpetrators, a majority of Thai adults, $76.87 \%$ of males and $75.72 \%$ of females reported that they had perpetrated against their partners at least one or more times in the past 12 months. For the prevalence of victimization, $74.23 \%$ of males and $69.78 \%$ of females reported that they had been perpetrated against by their partners (see Table 1).

The prevalence of psychological aggression was the highest, followed by physical assault, sexual coercion, and injury as the lowest. Examples of psychological aggression include insults, shouting or yelling, destroying something belonging to their partners, accusing their partners of being a lousy lover, and doing something to spite their partners. Examples of physical assault include pushing or shoving or twisting, throwing something at their partners that could hurt, and using a knife or gun. Sexual coercion examples are having sex without a condom, insisting on oral or anal sex (but without the use of physical force), using threats, and using force to make their partners have oral or anal sex. Injury examples include having a sprain, bruise, or small cut because of a fight with their partners, losing consciousness in a fight, and visiting a doctor because of a fight with their partners.

For the mean score of perpetration, male perpetrators' psychological aggression was highest, followed by sexual coercion, physical assault and the lowest mean was for injury. Female perpetrators' psychological aggression 
mean score was the highest, followed by physical assault, sexual coercion, and the lowest was for injury. When male and female perpetrators were compared, the patterns differed: the mean score of male physical assault on their partners' was lower than that of female physical assault on their partners, $(t(405)=-1.97, p<.05)$, but the mean score of male sexual coercion was higher than that of females, $(t(309)=5.14, p<.001)$. The total mean scores of male and female perpetrators were not significantly different. Moreover, the mean scores of victimization showed that male psychological aggression was the highest, followed by physical assault, sexual coercion, and the lowest was injury. For female victims, psychological aggression mean score was the highest, followed by sexual coercion, physical assault, and the lowest was injury. The mean score of male victims in psychological aggression was significantly higher than of female victims, $(t(662)=1.83, p<.05)$. Additionally, the mean score of male victims in physical assault was also significantly higher than of female victims, $(t(356)=$ $1.71, p<.05)$, though total mean scores of male and female victims did not significantly differ.

Table 1. Prevalence and forms of male and female perpetration and victimization $(N=1010)$

\begin{tabular}{|c|c|c|c|c|c|}
\hline \multirow{2}{*}{ Types of IPV } & \multicolumn{2}{|c|}{ Male } & \multicolumn{2}{|c|}{ Female } & \multirow[b]{2}{*}{$t$} \\
\hline & $n(\%)$ & $M(S D)$ & $n(\%)$ & $M(S D)$ & \\
\hline \multicolumn{6}{|l|}{ Perpetration } \\
\hline Psychological aggression & $323(71.15)$ & $1.94(3.07)$ & $395(71.04)$ & $2.04(3.27)$ & -0.49 \\
\hline Physical assault & 196(43.17) & $0.87(1.18)$ & 211(37.95) & $1.18(2.85)$ & $-1.97 *$ \\
\hline Sexual coercion & $179(39.43)$ & $1.72(3.73)$ & $132(23.74)$ & $0.72(2.06)$ & $5.14 * * *$ \\
\hline Injury & $106(23.35)$ & $0.53(2.22)$ & $76(13.67)$ & $0.45(1.97)$ & 0.59 \\
\hline Total & $349(76.87)$ & $1.42(2.28)$ & $421(75.72)$ & $1.25(2.00)$ & 1.26 \\
\hline \multicolumn{6}{|l|}{ Victimization } \\
\hline Psychological aggression & $316(69.60)$ & $2.09(3.47)$ & $348(62.59)$ & $1.71(3.25)$ & $1.83^{*}$ \\
\hline Physical assault & $192(43.17)$ & $1.14(2.62)$ & $166(29.86)$ & $0.86(2.53)$ & $1.71^{*}$ \\
\hline Sexual coercion & $156(34.36)$ & $1.13(2.84)$ & $165(29.68)$ & $1.13(2.63)$ & 0.01 \\
\hline Injury & $82(18.06)$ & $0.47(2.17)$ & $88(15.83)$ & $0.45(1.96)$ & 0.16 \\
\hline Total & $337(74.23)$ & $1.37(2.38)$ & $388(69.78)$ & $1.17(2.12)$ & 1.42 \\
\hline
\end{tabular}

Table 2. Correlations among childhood experiences, attachment, and IPV perpetration and victimization

\begin{tabular}{|c|c|c|c|c|c|c|c|c|c|c|c|c|c|c|c|c|c|c|}
\hline Variable & 1 & 2 & 3 & 4 & 5 & 6 & 7 & 8 & 9 & 10 & 11 & 12 & 13 & 14 & 15 & 16 & $M$ & $S D$ \\
\hline 1. Psy & - & $.67 * *$ & $.39 * *$ & $-.06^{*}$ & -.03 & $-.08 *$ & $.20 * *$ & $.25^{* *}$ & $.21 * *$ & $.17 * *$ & $.15^{* *}$ & $.10^{* *}$ & $.21 * *$ & $.16^{* *}$ & $.10 * *$ & $.10 * *$ & 3.13 & 5.30 \\
\hline 2. Phy & & - & $.46^{* *}$ & -.01 & .03 & -.01 & $.12 * *$ & $.20 * *$ & $.24 * *$ & $.23 * *$ & $.17 * *$ & $.17 * *$ & $.25^{* *}$ & $.19^{* *}$ & $.17^{* *}$ & $.17 * *$ & 3.57 & 4.93 \\
\hline 3. Negle & & & - & .06 & .06 & .04 & $.11 * *$ & $.14 * *$ & $.17 * *$ & $.18 * *$ & $.09 * *$ & $.15^{* *}$ & $.17 * *$ & $.15^{* *}$ & $.11 * *$ & $.15^{* *}$ & 3.57 & 5.70 \\
\hline 4. Love & & & & - & $.72 * *$ & $.60 * *$ & $-.23 * *$ & $-.23 * *$ & -.03 & .00 & $-.13 * *$ & $-.11 * *$ & -.05 & -.03 & $-.12 * *$ & $*-.11 * *$ & 17.23 & 7.99 \\
\hline 5. Inde & & & & & - & $.56^{* *}$ & $-.13 * *$ & $-.16 * *$ & -.04 & -.00 & $-.11 * *$ & $-.08 *$ & -.03 & -.02 & $-.11 * *$ & $*-.07 *$ & 16.25 & 8.12 \\
\hline 6. Model & & & & & & - & $-.28 * *$ & $-.32 * *$ & -.04 & -.04 & $-.11 * *$ & $-.11 * *$ & -.05 & -.04 & $-.10^{* *}$ & $*-.11 * *$ & 16.26 & 8.06 \\
\hline 7. Avoid & & & & & & & - & $.67 * *$ & $.16^{* *}$ & $.10 * *$ & $.10 * *$ & $.11 * *$ & $.23 * *$ & $.15^{* *}$ & $.10^{* *}$ & $.09 * *$ & 2.22 & 0.88 \\
\hline 8. Anxiety & & & & & & & & - & $.20 * *$ & $.16^{* *}$ & $.18 * *$ & $.13 * *$ & $.25 * *$ & $.19 * *$ & $.14 * *$ & $.13 * *$ & 2.56 & 0.89 \\
\hline 9. P_psy & & & & & & & & & - & $.67 * *$ & $.31 * *$ & $.33^{* *}$ & & & & & 1.99 & 3.18 \\
\hline 10. P_phy & & & & & & & & & & - & $.27 * *$ & $.45^{* *}$ & & & & & 1.04 & 2.58 \\
\hline 11. P_sex & & & & & & & & & & & - & $.39 * *$ & & & & & 1.17 & 2.97 \\
\hline 12. $P$ _injur & & & & & & & & & & & & - & & & & & 0.48 & 2.08 \\
\hline 13. V_psy & & & & & & & & & & & & & - & $.73 * *$ & $.38 * *$ & $.36^{* *}$ & 1.88 & 3.36 \\
\hline 14. V_phy & & & & & & & & & & & & & & - & $.41^{* *}$ & $.52 * *$ & 0.99 & 2.58 \\
\hline 15. V_sex & & & & & & & & & & & & & & & - & $.46^{* *}$ & 1.13 & 2.72 \\
\hline 16. V_injur & & & & & & & & & & & & & & & & - & 0.46 & 2.06 \\
\hline
\end{tabular}


Table 2 shows zero-order correlations for all variables included in IPV perpetration and victimization model. Abusive childhood experiences were significantly and positively correlated with adult attachment scores and IPV, whereas supportive childhood experiences were significantly and negatively correlated with adult attachment scores and sexual and injury IPV. Finally, both anxious and avoidant attachment styles were significantly and positively correlated with IPV.

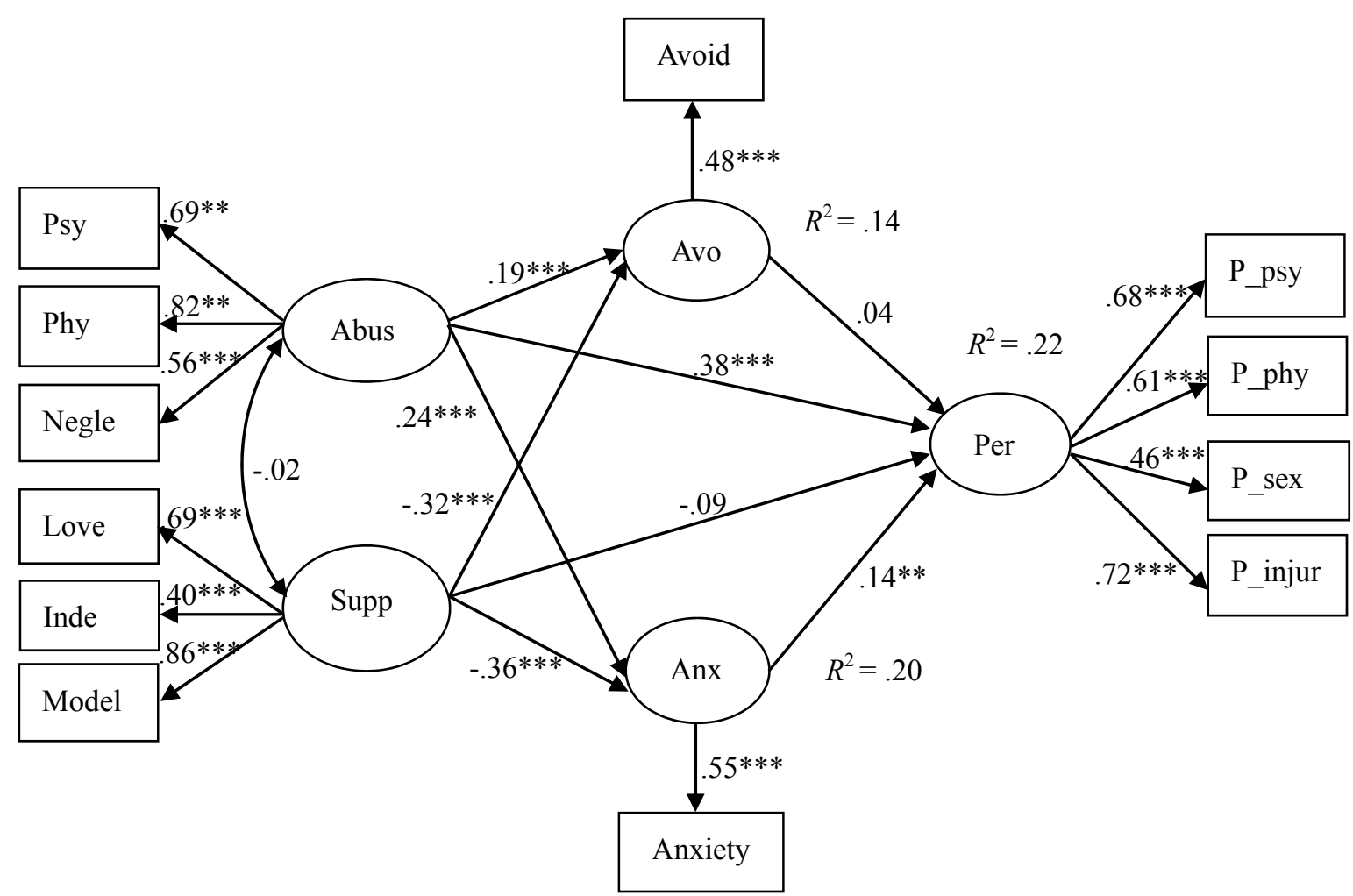

Figure 1. Structural equation modeling for childhood experiences, avoidance and anxiety attachment, and IPV perpetration

Chi square $=29.69(d f=21), p=.098 ; \mathrm{CFI}=1.00 ; \mathrm{RMSEA}=.020$

$* * p<.01 . * * * p<.001$.

\subsection{Structural Models for Relationships between Childhood Experiences, adult Attachment, and IPV}

Fit indices indicated that the model of the relationship between childhood experiences, adult attachment, and IPV perpetration fitted well with the data: $\chi^{2}(21)=29.69, p=.098, \mathrm{CFI}=1.00$, RMSEA $=.020$ (see Figure 1). With approximately $90 \%$ confidence, the RMSEA was between 0.00 and 0.036 . Figure 1 displayed the standardized coefficients and paths for the measurement model and the structural model. The analysis of the measurement model showed that each latent variable was well represented by its indicators.

The structural paths revealed that abusive experiences had the highest effect on IPV perpetration, $\beta=.38, p$ $<.001$, followed by indirect effects of supportive and abusive experiences through anxious attachment, $\beta=-.05$, $p=.007$ and $\beta=.03, p=.011$. However, supportive experiences had no effect on perpetration directly or indirectly through avoidant attachment.

For the victimization model in Figure 2, fit indices indicated that the model of the relationship between childhood experiences, adult attachment, and IPV victimization fitted with the data, $\chi^{2}(17)=27.46, p=.052$, $\mathrm{CFI}=1.00, \mathrm{RMSEA}=.025$. With approximately $90 \%$ confidence, the RMSEA was between .00 and .041. Figure 2 displayed the standardized coefficients and paths for the measurement model and the structural model. The analysis of the measurement model showed that each latent variable was well represented by its indicators. 


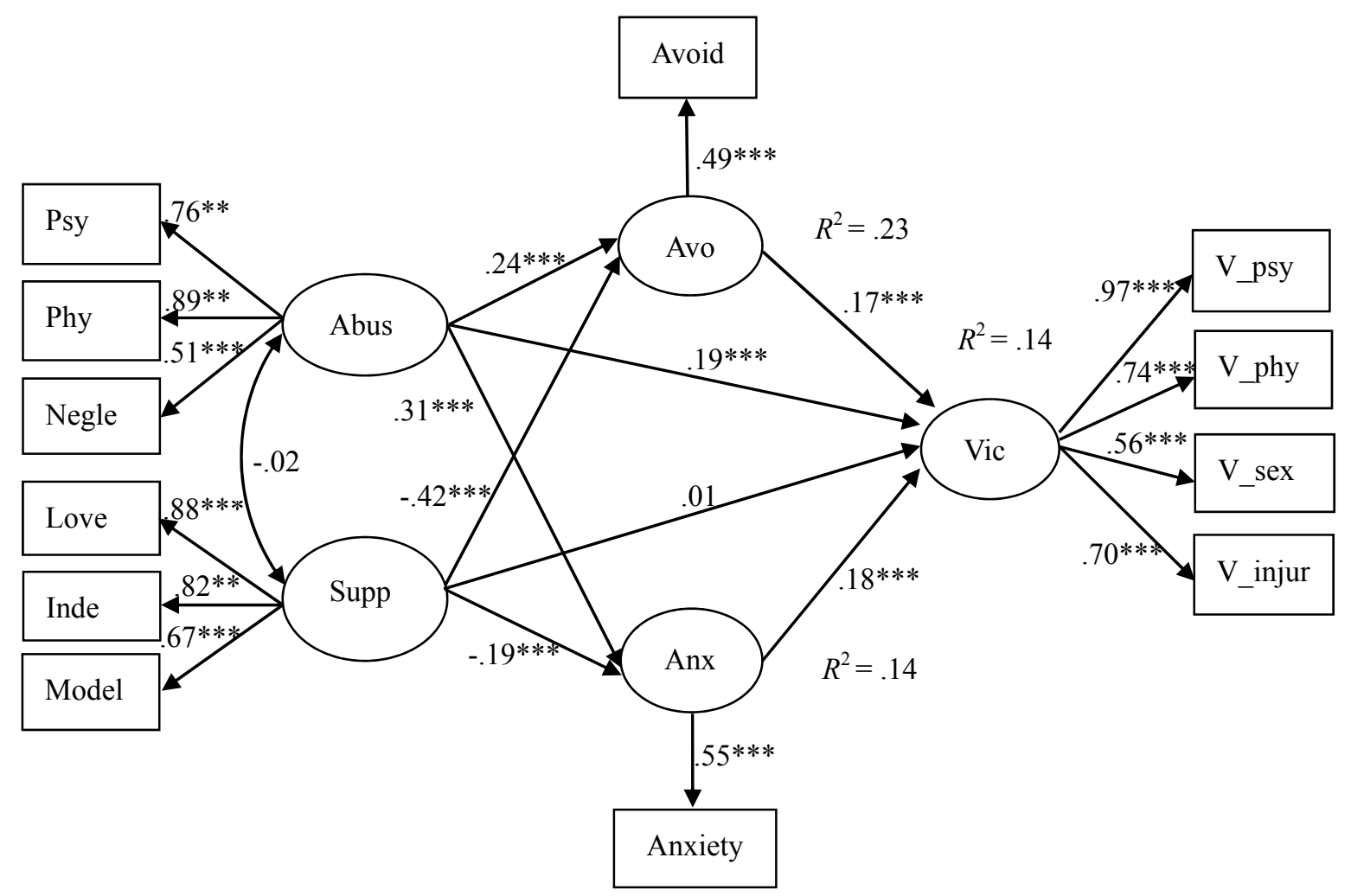

Figure 2. Structural equation modeling for childhood experiences, avoidance and anxiety attachment, and IPV victimization

Chi square $=27.46(d f=17), p=.052 ; \mathrm{CFI}=1.00 ; \mathrm{RMSEA}=.025$

$* * p<.01 . * * * p .001$.

It was found that abusive experiences directly affected IPV victimization the highest, $\beta=.19, p<.001$, followed by supportive experiences indirectly affected through avoidant attachment, $\beta=-.07, p<.001$. Following this, abusive experiences are indirectly affected through anxious attachment, $\beta=.06, p<.001$, and avoidant attachment, $\beta=.04, p<.001$. The least effect was supportive experiences on IPV victimization through anxious attachment, $\beta=-.03, p<.001$, in addition, supportive experiences had no effect on victimization.

\section{Discussion}

Regarding the prevalence and forms of IPV perpetration in this research, the results showed that $76.87 \%$ of males and $75.72 \%$ of females reported IPV perpetration of one or more types on intimate partners in the past year. Psychological aggression scores were highest, followed by physical assault, sexual coercion, and the lowest score was for injury. As we can see, the current research reports that nearly all forms of violence were higher than what the Thailand Domestic Violence Information Center (2013) reported, apart from male physical assault perpetration and female physical assault victimization which were marginally lower than the Thailand Domestic Violence Information Center's findings. However, it was found that the prevalence of female victimization in terms of physical assault and sexual coercion seemed equal to what reported in Atchawanitchakun, kanchanajitra, Im-em, and Lertsrisantad (2003)'s study, but the injury ratio in the present study was lower than their findings. These differences might be the result of the data collection methods. In the Thailand Domestic Violence Information Center report, the data was collected from cases who sought help and reported the domestic violence to the authorities in the participating provinces, especially severe cases. The present study and Atchawanitchakun et al. collected data from the fieldwork.

However, male perpetrators reported higher mean scores than female perpetrators in sexual coercion, in contrast, female perpetrators reported a higher mean score than did male perpetrators in physical assault, such as pushing, shoving and twisting. These findings are congruent with past research findings (Hickman, Jaycox, \& Aronoff, 2004; Péloquin, Lafontaine, \& Brassard, 2011; Straus et al., 1996) in which females reported higher physical 
assault perpetration than males, but males reported higher sexual coercion perpetration than females. This gender difference might reflect Thai society's thoughts and beliefs surrounding sexual issues in which females are taught to be more inhibited and more reserved when talking about sex in public. The issue is covert and seen as something to be dealt with privately, so it can be seen as a cultural hindrance. Thai values have taught women to accept and tolerate domestic violence; especially sexual violence and as a result many who have experienced sexual violence with their partners were unwilling to reveal this. Added to this is the presence of a patriarchal society, resulting in many men exhibiting sexual power over their partners as a given right in their eyes, which in turn may lead to conflict and dissatisfaction with sexual problems and possibly end in domestic violence (Pipitkul \& Gunpai, 2003).

Regarding the results of structural equation modeling, we found that IPV perpetration and victimization were due to the direct effect of abusive experiences. This can be explained by social learning theory. Children who experience family violence often view it as acceptable because they have yet to develop critical thinking skills at that stage in their lives, so they may believe that their parents' behavior is natural and acceptable and may be more likely to emulate this behavior in the future (Bensley, Eenwyk, \& Simmons, 2003; Dutton, 1999; Feldman, 1997; Foshee, Bauman, \& Linder, 1999; Garvey et al., 1999; Lewis \& Fremouw, 2001). The violent circumstances that these children find themselves in lays the ground for their development, understanding and subsequent behavior surrounding relationships, making them more prone to becoming perpetrators and victims when they eventually find partners.

Moreover, we found indirect effects of abusive and supportive experiences on rates of IPV perpetration mediated by anxiety over abandonment. Children who had been physically abused demonstrated avoidant attachment; meanwhile, children who were neglected by their parents became anxiously attached (Finzi, Ram, Har-Even, Shnit, \& Weizman, 2001). Moreover, adult attachment styles can predict relationships to their caretakers, as indicated by Hazan and Shaver (1987) who reported that people who often avoided intimacy said that their mothers were cold and rejected them, and that those who were anxiously attached reported that their fathers had treated them unfairly. This finding is supported in a number of studies (Godbout et al., 2009; Mikulincer \& Shaver, 2003) in which perpetrators with anxious attachment are prone to abuse their partners more than those with avoidant attachment because the anxiously attached are likely to show relatively constant awareness of negative feelings. They focus their attention on these feelings in a hypervigilant way and display heightened expressions of fear and anger, while the avoidant type is cold and distant, tending to distance themselves from situations. Similarly, Orcutt et al. (2005) reported that females who had a high degree of anxious attachment and a low degree of avoidant attachment were prone to perpetrate their partners more than those who had high degrees of both attachment styles. In addition, Péloquin et al. (2011) also found that avoidant attachment could predict perpetration in females, but that this was not indicative of males.

The antecedents of IPV victimization also included abusive experiences and this finding is also congruent with social learning theory. However, this indirect effect of abusive experiences on victimization was mediated through anxiety over abandonment and avoidance of intimacy. Withdrawal (avoidance of intimacy) could provoke partner's aggressive behaviors; this could explain why males with anxious attachment more often reported victimizing their partners (Roberts \& Noller, 1998). Wife withdrawal has been found to be a significant predictor of husband violence (Babcock, Jacobson, Gottman, \& Yerington, 2000). Perpetrators in the current study, however, based on informal observations, often had situational misperceptions. When their partners withdrew from conflict situations to manage their spouses who had anxious attachment, those spouses began to use psychological aggression, and eventually physical assault. Perhaps perpetrators with anxious attachment felt anxious about abandonment, may have misperceived their partners' withdrawal as the end of their relationship, driving them to react violently with the aim to try to gain control of the situation (Jordan, 1997). Similarly, Orcutt et al. (2005) found that female perpetrators and victims reported that they were highly anxiously attached.

This study revealed that abusive experiences had the highest direct effect on perpetration and victimization. However, supportive experiences had a greater negative effect on perpetration than the positive effects of abusive experiences, nearly doubling the effect, through anxiety over abandonment. In addition, supportive experiences produced marginally higher negative effects on victimization through avoidance of intimacy compared with the positive effects of abusive experiences through anxiety over abandonment. This was followed by abusive experiences which had slightly higher positive effects on victimization through avoidance of intimacy compared with the negative effects of supportive experiences through anxiety over abandonment.

Finally, the current results suggest that abusive experiences often lead children to develop unhealthy intimate relationships when they grow up, especially if they have experienced physical assault. However, supportive experiences such as good modeling appear to prevent the development of IPV perpetration later on in life. 
Considering this we can deduce that fostering more supportive experiences during childhood, such as displaying affection towards a child, may prevent victimization later on in life.

\section{Limitations}

One limitation of the current study was that most of the participants were employed in public and private sectors, and their social economic statuses tended to be at moderate levels, so they may not be representative of all heterosexual partner populations in Thailand. A number of studies have found that poverty or low income partners struggle even more with IPV (Harvey, Garcia-Moreno, \& Butchart, 2007).

Secondly, the current measures were self-report questionnaires, composed of affectively negative information about their families. Participants may have been prone to underestimated domestic violence in their youth.

Thirdly, participants in this research were solely adults. The occurrence of dating violence is increasing, and it has been reported that the mean perpetration score of girls is higher than boys, but that this statistic with girls will decrease when they become adults. In contrast, the boys' mean score increases after adulthood (Fernández-Fuertes \& Fuertes, 2010; O’Leary, Slep, Avery-Leaf, \& Cascardi, 2008).

Fourthly, this research looked at domestic violence in the contexts of partner-partner and parent-to-child violence. However, domestic violence in Thailand also extends to other contexts such as child-parent and abuse towards elderly family members. There is scope for future research into these contexts of domestic violence.

\section{Implications of Interventions}

The present study revealed the prevalence and forms of IPV perpetration and victimization in four types of violence, psychological aggression, physical assault, sexual coercion, and injury. Moreover, it acts as a guide for parent and couple interventions in order to prevent domestic violence. The Ministry of Social Development and Human Security and Thailand UNICEF (2015) have acquired knowledge and understanding about child maltreatment and have promoted an end to the violence against children by creating projects that aim to change the negative parenting attitudes and behaviors which contribute towards child abuse. These projects make parents aware of the consequences of their actions and aim to promote supportive behavior towards their children accompanied by positive disciplining. The implications for the abused partner are the necessities of leaving from violent situations, being aware of sexual equality, and having a right to make accusations against perpetrators. Note that partners may arouse or suppress violence by positive verbal communication and that victimization needs to be dealt with carefully. Additionally, social services were approached to deal with violent situations, which they dealt with by; giving counsel to the partners, restoring male perpetrators, promoting sexual equality, and developing multidisciplinary teams to solve the violence problems (Women and Men Progressive Movement Foundation, 2015).

The current research found that both supportive and abusive experiences from caretakers can explain IPV rates, and this suggests that positive parenting practices is an important preventative tool for IPV is positive parenting practices. In cases of abusive childhood experiences, physical assault is most directly affected IPV perpetration. Therefore, reducing physical assault; for example, throwing things at, hitting, or beating children can protect adults from emulating this behavior towards their future partner. Moreover, abusive and supportive childhood experiences were mediated by anxiety over abandonment. The implications are the necessity of increasing supportive childhood experiences, especially positive modeling and fairness (such as practicing what you preach, setting good examples, and being fair).

In the case of victimization, abusive childhood experiences, especially physical assault, contributes most towards IPV victimization and this is followed by psychological aggression. Therefore, reducing physical assault is essential in order to prevent adults from victimization, including psychological aggression (such as being insulted or sworn at, having personal belongings destroyed, and accusations of being an inadequate lover). Moreover, abusive and supportive childhood experiences were mediated by anxiety over abandonment and avoidance of intimacy. There needs to be an increase in supportive childhood experiences, especially giving love and support to a child, such as believing in the child, doing things that let the child know their parents love them, and helping the child when they are in trouble. Moreover, promoting independency towards children can also prevent victimization; such as letting a child feel in control of their own life, allowing the child to explore their own beliefs, and allowing them to be as independent and free as they need to be.

The results of the current study suggest that reducing abusive childhood experiences can reduce IPV. Preventive implications should consider all the processes. Partner violence occurs in families, which also unexpectedly affects their children. IPV can destroy parent-child relationships because a couple's stress may create emotional distances between parents and children (Stasiak, Davies, Koziol-McLain, \& Hanna, 2004). More than half (57\%) 
of children who witness parental violence had direct abusive childhood experiences. It was found that IPV and child abuse occurred at the same time. In addition, $34 \%$ of children who witness parental violence have experienced physical, psychological, neglect, or sexual violence (Hamby, Finkelhor, Turner, \& Ormrod, 2010). From 2004 to 2013 there were 98211 cases of Thai children seeking help from the One Stop Crisis Center (OSCC), which was established with the aim of helping women and children suffering from violence (Ministry of Social Development and Human Security Operation Center, 2014). These abusive childhood factors have several negative consequences for development such as causing anxiety, low self-identity, anger, acceptance of the perpetrator's views, anti-social behavior, disrespectful communication, withdrawal, unsuccessful or insecure attachment, and unhealthy relationships with others (Murphy, Paton, Gulliver, \& Fanshow, 2013). Insecure attachment leads to IPV and probably the direct or indirect abuse of children in their family and in turn the cycle of violence will continue.

In contrast, supportive childhood experiences can protect children from an insecure attachment style and IPV when they are adults, especially if they are shown love and support and have been shown good models of fairness, which are better than when verbal preaching occurs without a demonstration of practicing what you preach. It strengthened parent-child relationships because supportive experiences are predictable and promote consistent environments between children and caregivers. They can create working models of their social worlds predictable and manageable, and learn how to respond appropriately to relationship partners. If they have inadequate relationship circumstances, they will be at risk of other violence (Centers for Disease Control and Prevention, 2014). Positive consequence of supportive childhood experiences is coherence relationship and restoring detrimental relationship due to violence (Humphreys, 2010). Finally, they enjoy a heightened effectiveness of communication and emotional support, which reduced domestic violence and its effects on children (Murphy et al., 2013).

Furthermore, anxiety over abandonment is a strong mediator from childhood experiences to IPV perpetration and victimization, whereas avoidance to intimacy is a mediator in a victimization model. So adults should probably choose a partner with a secure attachment style and work on developing themselves in that relationship, otherwise the implications for those whose partners have insecure attachments are screening and fulfilling their needs. Attachment anxiety is characterized by feeling anxious and worried about whether one's partner is available and responsive and those who have high attachment anxiety are fearful of rejection and abandonment. Attachment avoidance is characterized by distancing others or avoiding the disclosure of feelings of one's significant other, and those who have high avoidance attachment are uncomfortable with closeness or depending on others, which might increase the chance of conflict and violence (Fraley \& Shaver, 2000). Later, adults should satisfy their insecurely attached partners by making them feel worthwhile and not inferior in their view. They should also avoid situations of conflict and learn to read signals that preempt potential violent situations from occurring and withdraw from those situations until their partner is in a calmer state of mind. In addition, Cozzarelli, Karafa, Collins, and Tagler (2003) suggested that individuals who become more secure over time report increases in self-esteem and perceived social support and decreases in perceived social conflict. These adults should now give social support to their insecure partners in order to increase their self-esteem and reduce the conflict that leads to their partner's violent behavior. Finally, the implications for parents are to make the attachment style with children trustable, predictable and dependable (Mikulincer \& Florian, 1998); moreover, expressing their feelings and accepting their children as whom they are, making them as comfortable as possible (Brennan, Clark, \& Shaver, 1998).

\section{Conclusion}

Antecedences of IPV are found in abusive childhood experiences which affect perpetration directly and indirectly through anxiety over abandonment. Additionally abusive childhood experiences affect victimization directly and indirectly through anxiety over abandonment and avoidance of intimacy. However, supportive childhood experiences affect perpetration indirectly through reduced anxiety over abandonment and affect victimization indirectly through reduced anxiety over abandonment and avoidance of intimacy. The current study supports reducing abusive childhood experience; especially physical assault, and enhancing supportive childhood experiences, especially good model behaviors in order to reduce IPV.

\section{Acknowledgements}

This research was supported by THE $90^{\text {th }}$ ANNIVERSARY OF CHULALONGKORN UNIVERSITY FUND (Ratchadaphiseksomphot Endowment fund) and approved by Chulalongkorn University Institutional Review Board (IRB). 


\section{References}

Ainsworth, M. D. S., Blehar, M. C., Waters, E., \& Wall, S. (1978). Patterns of attachment: A psychological study of the strange situation. Hillsdale, NJ: Erlbaum. http://dx.doi.org/10.1002/1097-0355(198021)1:1 $<68::$ AID-IMHJ2280010110>3.0.CO;2-3

Atchawanitchakun, K., Kanchanajitra, C., Im-em, W., \& Lertsrisanthat, U. (2003). Intimate partner violence and women's health in Thailand. Nakhon Pathom: Institute for Population and Social Research, Mahidol University, Thailand.

Babcock, J. C., Jacobson, N. S., Gottman, J. M., \& Yerington, T. P. (2000). Attachment, emotional regulation, and the function of marital violence: Differences between secure, preoccupied, and dismissing violent and nonviolent husbands. Journal of Family Violence, 15(4), 391-409. http://dx.doi.org/10.1023/A:100755833 0501

Bandura, A. (1973). Aggression: A social learning analysis. Englewood Cliffs, NJ: Prentice-Hall.

Bandura, A., \& Walters, R. (1963). Social learning and personality development. New York, NY: Holt, Rinehart $\&$ Winston.

Bensley, L., Eenwyk, J. V., \& Simmons, K. W. (2003). Childhood family violence history and women's risk for intimate partner violence and poor health. American Journal of Preventive Medicine, 25, 38-44. http://dx.doi.org/10.1016/S0749-3797(03)00094-1

Bowlby, J. (1984). Violence in the family as a disorder of the attachment and caregiving systems. American Journal of Psychoanalysis, 44, 9-27.

Brennan, K. A., Clark, C. L., \& Shaver, P. R. (1998). Self-report measurement of adult attachment: An integrative overview. In J. A. Simpson, \& W. S. Rholes (Eds.), Attachement theory and close relationships (pp. 44-76). New York, NY: Guilford Press.

Centers for Disease Control and Prevention. (2014). Strategic direction for child maltreatment. Retrieved from http://www.cdc.gov/violenceprevention/overview/strategicdirections.html

Cozzarelli, C., Karafa, J. A., Collins, N. L., \& Tagler, M. J. (2003). Stability and change in adult attachment styles: Associations with personal vulnerabilities, life events, and global construals of self and others. Journal of Social and Clinical Psychology, 22(3), 315-346. http://dx.doi.org/10.1521/jscp.22.3.315.22888

Dutton, D. G. (1999). Traumatic origins of intimate rage. Aggression and Violent Behavior, 4(4), 431-447. http://dx.doi.org/10.1016/S1359-1789(98)00027-5

Feldman, C. M. (1997). Childhood precursors of adult interpartner violence. Clinical Psychology: Science and Practice, 4(4), 307-334. http://dx.doi.org/10.1111/j.1468-2850.1997.tb00124.x

Fernández-Fuertes, A. A., \& Fuertes, A. (2010). Physical and psychological aggression in dating relationships of Spanish adolescents: Motives and consequences. Child Abuse \& Neglect, 34(3), 183-191. http://dx.doi.org/10.1016/j.chiabu.2010.01.002

Finzi, R., Ram, A., Har-Even, D., Shnit, D., \& Weizman, A. (2001). Attachment styles and aggression in physically abused and neglected children. Journal of Youth and Adolescence, 30(6), 769-786. http://dx.doi.org/10.1023/A:1012237813771

Foshee, V. A., Bauman, K., \& Linder, G. (1999). Family violence and the perpetration of adolescent dating violence: Examining social learning and control processes. Journal of Marriage and Family, 61, 331-342.

Fraley, R. C., \& Shaver, P. R. (2000). Adult romantic attachment: Theoretical developments, emerging controversies, and unanswered questions. Review of General Psychology, 4(2), 132-154. http://dx.doi.org/10. 1037/1089-2680.4.2.132

Fraley, R. C., Waller, N. G., \& Brennan, K. A. (2000). An item response theory analysis of self-report measures of adult attachment. Journal of Personality and Social Psychology, 78(2), 350-365. http://dx.doi.org/10. 1037/0022-3514.78.2.350

Garvey, S., McDowell, M., \& Streit, L. (1999). The effects of domestic violence on children. Paper presented at the skillenium 2000 meeting foe CWLA, Miami, FL.

Godbout, N., Dutton, D. G., Lussier, Y., \& Sabourin, S. (2009). Early exposure to violence, domestic violence, attachment representations, and marital adjustment. Personal Relationships, 16, 365-384. http://dx.doi.org/10.1111/j.1475-6811.2009.01228.x 
Griffin, D. W., \& Bartholomew, K. (1994). The metaphysics of measurement: The case of adult attachment. Advances in Personal Relationships, 5, 17-52.

Hamby, S., Finkelhor, D., Turner, H., \& Ormrod, R. (2010). The overlap of witnessing partner violence with child maltreatment and other victimizations in a nationally representative survey of youth. Child Abuse and Neglect, 34(10), 734-741. http://dx.doi.org/10.1016/j.chiabu.2010.03.001

Harvey, A, Garcia-Moreno, C., \& Butchart, A. (May 2-3, 2007). Primary prevention of intimate-partner violence and sexual violence. Background paper for WHO expert meeting. Retrieved from http://www.who.int/ violence_injury_prevention/publications/violence/IPV-SV.pdf

Hazan, C., \& Shaver, P. (1987). Romantic love conceptualized as an attachment process. Journal of Personality and Social Psychology, 52(3), 511-524. http://dx.doi.org/10.1037/0022-3514.52.3.511

Hickman, I. J., Jaycox, L. H., \& Aronoff, J. (2004). Dating violence among adolescents: Prevalence, gender distribution, and prevention program effectiveness. Trauma, Violence and Abuse, 5, 123-142. http://dx.doi.org/10.1177/1524838003262332

Humphreys, C. (2010). Crossing the great divide: Response to Douglas and Walsh. Violence against Women, 16(5), 509-515. http://dx.doi.org/10.1177/1077801210366288

Imthanavanich, P. (2002). Motivation for unreciprocated love and attachment styles as predictors of intensity and experiences of unreciprocated love (Unpublished master's thesis). Chulalongkorn University, Thailand.

Jordan, J. V. (Ed.). (1997). Women's growth in diversity: More writings from the Stone Center. New York, NY: Guilford Press.

Lawson, D. M. (2008). Attachment, interpersonal problems, and family of origin functioning: Differences between partner violent and nonpartner violent men. Psychology of Men and Masculinity, 9, 90-105.

Lewis, S. F., \& Fremouw, W. (2001). Dating violence: A critical review of the literature. Clinical Psychology Review, 2l(1), 105-127. http://dx.doi.org/10.1016/S0272-7358(99)00042-2

Marcus, R. F., \& Swett, B. (2003). Violence in close relationships: The role of emotion. Aggression and Violent Behavior, 8(3), 313-327. http://dx.doi.org/10.1016/S1359-1789(01)00070-2

McKinney, C. M., Caetano, R., Ramisetty-Mikler, S., \& Nelson, S. (2009). Childhood family violence and perpetration and victimization of intimate partner violence: Findings from a national population-based study of couples. Association of Educational Psychologists Journal, 19, 25-32. http://dx.doi.org/10.1016/j.anne pidem.2008.08.008

Mikulincer, M., \& Florian, V. (1998). The relationship between adult attachment styles and emotional and cognitive reactions to stressful events. In J. A. Simpson, \& W. S. Rholes (Eds.), Attachment theory and close relationships (pp. 143-165). New York, NY: Guilford.

Mikulincer, M., \& Shaver, P. R. (2003). The attachment behavioral system in adulthood: Activation, psychodynamics, and interpersonal processes. In M. P. Zanna (Ed.), Advances in experimental social psychology (Vol. 35, pp. 53-152). New York, NY: Academic Press.

Ministry of Social Development and Human Security and Thailand UNICEF. (2015). Child maltreatment effects. Retrieved from http://endviolencethailand.org/violence_effect_on_youth

Ministry of Social Development and Human Security Operation Center. (2014). Daily situation summary report. Retrieved from http://moc.m-society.go.th/?wpfb_dl=62

Murphy, C., Paton, N., Gulliver, P., \& Fanshow, J. (2013). Understanding connections and relationships: Child maltreatment, intimate partner violence and parenting. New Zealand Family Violence Clearinghouse, paper 3. Retrieved from https://nzfvc.org.nz/sites/nzfvc.org.nz/files/issues-paper-3-2013.pdf

Nicholas, K. B., \& Bieber, S. L. (1997). Assessment of perceived parenting behaviors: The exposure to abusive and supportive environments parenting inventory (EASE-PI). Journal of Family Violence, 12(3), 275-291. http://dx.doi.org/10.1023/A:1022848820975

O’Leary, K. D., \& Curley, A. D. (1986). Assertion and family violence: Correlates of spouse abuse. Journal of Marital and Family Therapy, 12(3), 281-290. http://dx.doi.org/10.1111/j.1752-0606.1986.tb00654.x

O’Leary, K. D., Slep, A. M. S., Avery-Leaf, S., \& Cascardi, M. (2008). Gender differences in dating aggression among multiethnic high school students. Journal of Adolescent Health, 42(5), 473-479.

Orcutt, H. K., Garcia, M., \& Pickett, S. M. (2005). Female-perpetrated intimate partner violence and romantic 
attachment style in a college student sample. Violence and Victims, 20(3), 287- 302.

Parapop, O. (2003). Attachment styles and causal attribution of one's own behaviors versus other's behaviors in negative situations (Unpublished master's thesis). Chulalongkorn University, Thailand.

Péloquin, K., Lafontaine, M.-F., \& Brassard, A. (2011). A dyadic approach to the study of romantic attachment, dyadic empathy, and psychological partner aggression. Journal of Social and Personal relationships, 28(7), 915-942. http://dx.doi.org/doi:10.1177/0265407510397988

Pipitkul, W., \& Gunpai, K. (2003). Sex and communication in Thai society. Research report, The Thailand Research Fund.

Roberts, N., \& Noller, P. (1998). The associations between adult attachment and couple violence: The role of communication patterns and relationship satisfaction. In J. A. Simpson, \& W. S. Rholes (Eds.), Attachment theory and close relationships (pp. 317-350). New York, NY: Guilford Press.

Stasiak, K., Davies, E., Koziol-McLain, J., \& Hanna, K. (2004). Incubated in terror: Children living with domestic violence. Te Awatea Review, 2(1), 3-5.

Straus, M. A., Hamby, S. L., Boney-Mccoy, S., \& Sugarman, D. B. (1996). The revised Conflict Tactics Scales (CTS2): Development and preliminary psychometric data. Journal of Family Issues, 17(3), 283-316. http://dx.doi.org/10.1177/019251396017003001

Straus, M. A., Hamby, S. L., Finkelhor, D., Moore, D. W., \& Runyan, D. (1998). Identification of child maltreatment with the Parent-Child Conflict Tactics Scales: Development and psychometric data for a national sample of American parents. Child Abuse \& Neglect, 22, 249-270. http://dx.doi.org/10.1016/ S0145-2134(97)00174-9

Tantong, A. (2005). Interpersonal attraction and attachment styles: Self similarity, complementarity, and attachment security (Unpublished master's thesis). Chulalongkorn University, Thailand.

Thailand Domestic Violence Information Center. (2013). Number of domestic violence situation. Retrieved from http://www.violence.in.th/violence/report/violence/report.aspx?event_status $=2 \&$ relation_type $=0 \&$ category $=$ $0 \&$ order_by $=0$ \&year $=2013 \&$ province $=1$

UN Women. (2011). 2001-2012 Progress of the world's women: In pursuit of justice. Retrieved from http://www.unwomen.org/en/digital-library/publications/2011/7/progress-of-the-world-s-women-in-pursuitof-justice

Women and Men Progressive Movement Foundation. (2015). Activities of Women and Men Progressive Movement Foundation. Retrieved from http://www.wmp.or.th/pages/view/6

\section{Copyrights}

Copyright for this article is retained by the author(s), with first publication rights granted to the journal.

This is an open-access article distributed under the terms and conditions of the Creative Commons Attribution license (http://creativecommons.org/licenses/by/4.0/). 